\title{
Determination of Rolling Mill Roller Load during Procurement Transportation
}

\author{
Mariya Androsenko*, Irina Savelyeva, Ivan Krayniy, Ivan Demidov, and Irina Deeva \\ Nosov Magnitogorsk State Technical University, Lenin Avenue 38, Magnitogorsk, postcode 455000, Russia
}

\begin{abstract}
The paper shows how to calculate the loads on conveyor rollers at different positions of the conveyed billet. It also contains the diagrams of conveyors with different types of drives and loading diagrams as well.
\end{abstract}

\section{Introduction}

Great variety of roller conveyors designs is one of the problems related to their operation. Every design has both advantages and disadvantages that influence its maintainability.

\section{Main part}

The structural model of roller conveyors usually consists of electrical motor (EM), gear reduction unit (GRU), transfer gearbox (TGB), conveyor frame (CF), transmission shaft (TSh), conveyor roller (CR). In accordance with this the roller table structural model is shown below [1]:

$$
\mathrm{EM}+\mathrm{GRU}+\mathrm{TGB}+\mathrm{CF}+\mathrm{TSh}+\mathrm{CR} .
$$

As applied to roller conveyors (roller tables) of wide-strip rolling mill [2] the structural models defined by the number and types of components are the following:

roughing roller tables between stands

$$
\mathrm{EM}+\mathrm{GRU}+\mathrm{TGB}+\mathrm{CF}+\mathrm{TSh}+\mathrm{CR} .
$$

intermediate roller table

$$
\mathrm{EM}+\mathrm{CF}+\mathrm{TSh}+\mathrm{CR}
$$

furnace table

$$
\mathrm{EM}+\mathrm{GRU}+\mathrm{TSh}+\mathrm{CR}+\mathrm{CF} .
$$

Roller tables are mechanisms for continuous conveying; they play an important role in auxiliary operations of rolling mills. In accordance with their functions all roller tables can be nominally divided into the following main types: main tables, carry-over tables, furnace tables, lifting and tilting tables, lifting and disappearing tables, branch roller tables, travelling roller tables and etc.

\footnotetext{
* Corresponding author: manechka.05@mail.ru
} 
According to the type of drive the roller tables can be divided into roller tables with a group drive or an individual drive (fig. 1).
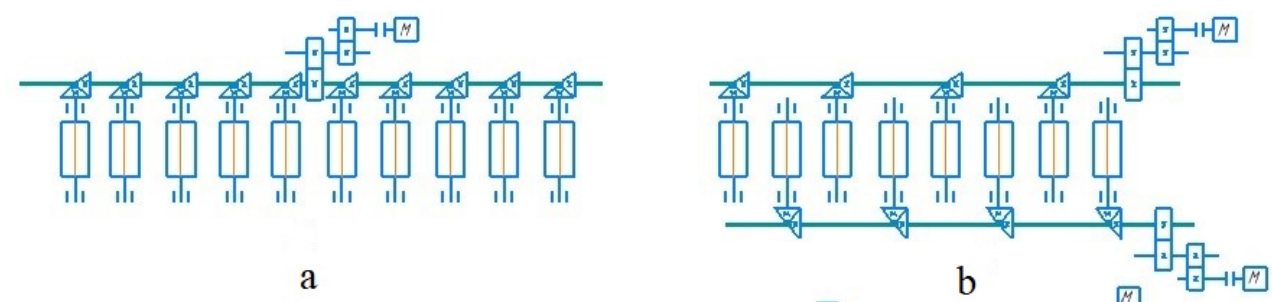

a

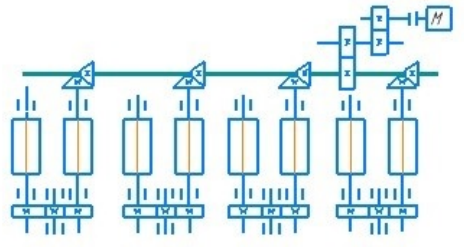

$\mathrm{C}$

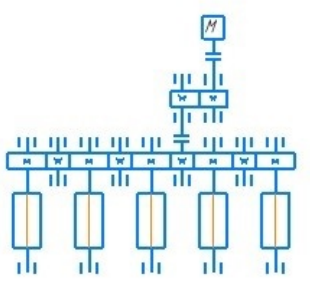

d

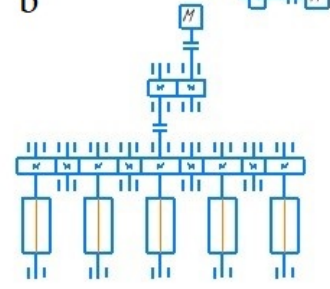

f

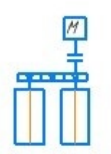

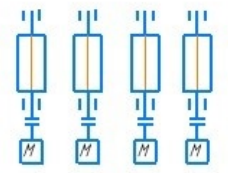

$\mathrm{g}$
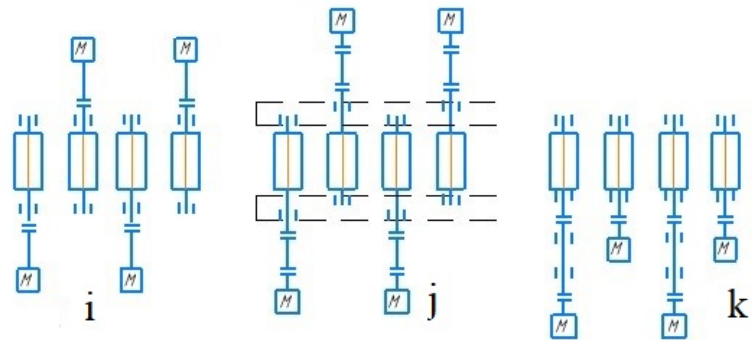

Fig. 1. Diagrams of roller tables with group and individual drive [3].

Advantages of roller tables over other types of transportation:

1. Transportation of heavy hot product.

2. Manoeuvrability due to fast reversing motion. As a roller table can consist of several sections it is possible to adjust speed of rolling mill products movement at its different areas. It allows to speed up the rolling product at the beginning of the roller table, to slow down the rolling product at the other end of the roller table and to form the packages,

3. Case-specific approach to the design choice of particular roller table areas on the basis of the load and operation conditions.

4. Convenient arrangement with adjacent equipment.

5. Relatively low power consumption.

6. $\quad$ Fixedness of friction units.

Roller tables with an individual drive are widely used as they are easier to repair and require less maintenance in comparison with the roller tables with the group drive.

A roller table can operate in one of the following modes: - conveying of the slab and billet; billet turning; no load operation; coming out of the billet from the stand. All the above mentioned modes can be characterised by different loads on the roller table components,

Conveyor rollers transport the slab that is why loads on the roller table are considered with regards to its rollers which take up pressure from the slab and transfer this pressure onto bearing supports.

The loads on the roller table bearings, gears, tooth gears, gear system, gear shaft, 
couplings and etc. can be calculated on the basis of defined loads on the rollers. The main mode of a roller table (with respect to the time periods) is the conveying of the slab and a billet. The load onto the rollers depends on the slab (billet) mass and its length for this mode.

The load per roller is inversely related to the number of rollers that simultaneously come into contact with the conveying metal. Each pass in the rolling stand elongates the process workpiece so its mass is distributed onto a larger number of rollers. The load per roller decreases and the torque moment transferred to the elements of the roller tables reduces as well.

Figures 2 -3 show the main loading diagrams of the conveyor rollers during the billet transportation.

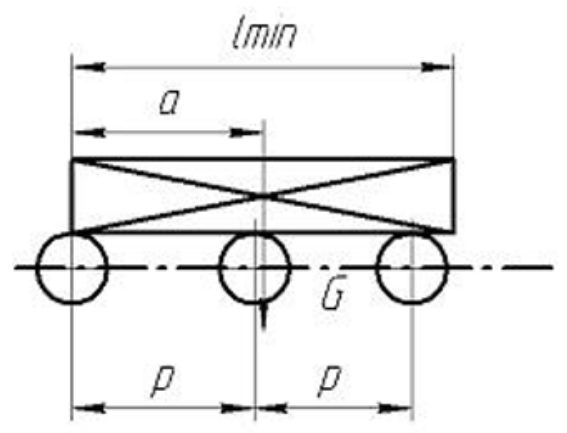

Fig. 2. Roller table loading diagram during slab conveying.

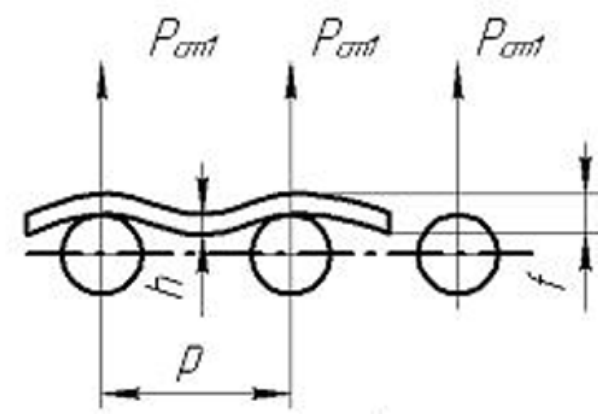

Fig. 3. Roller table loading diagram during workpiece conveying.

According to the source [4] it is considered that three rollers take up the mass of the conveyed slab (fig.2).

The load onto one roller can be defined as billet mass related to the number of rollers on which it rests (fig.3) in case the length of the conveyed billet exceeds two roller spacings.

But in practice, the billet contacts with $70 \%$ of the total number of rollers. It can be explained by the fact that a certain number of rollers do not directly contact with the billet because of its unevenness.

When the roller table is idle, the rollers take up the load only from their own gravity force.

Dynamic force influences the rollers in the billet turning mode.

The scheme of influence of dynamic forces on conveyor rollers during turning process is shown in figure 4 . 


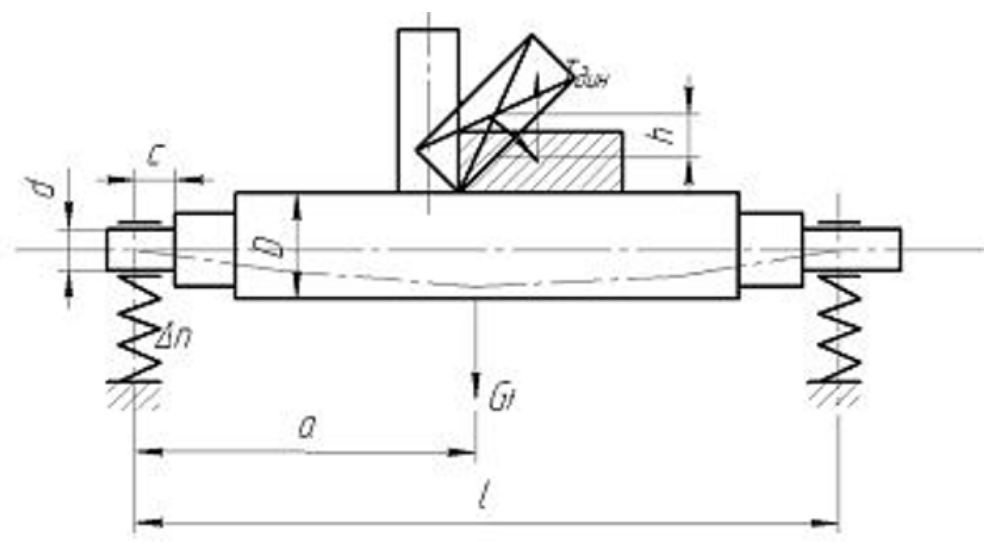

Fig. 4. The scheme of influence of dynamic forces on conveyor rollers during turning process.

Moreover, dynamic force influences conveyor rollers at the output of the billet from the stand.

Two variants of output of the billet from the stand are possible. The schemes of which are shown in figures 5 and 6.

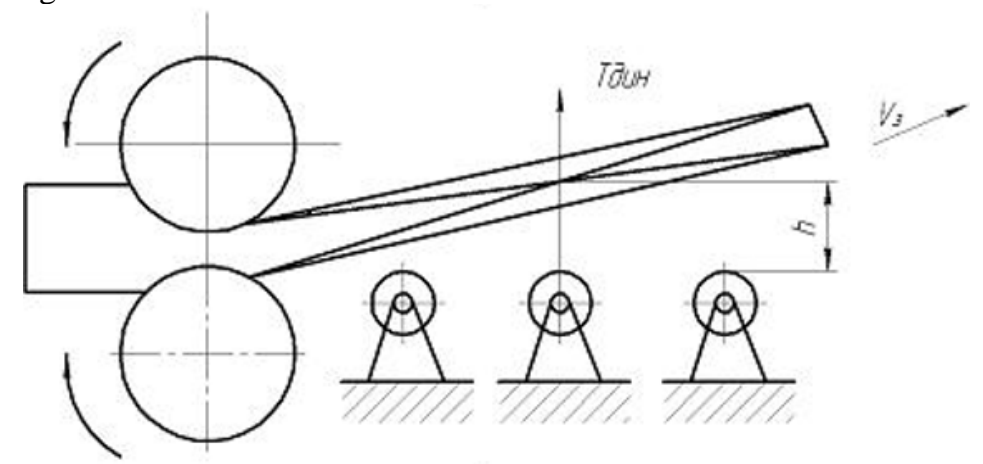

Fig. 5. The scheme of the influence of dynamic forces on the conveyor rollers during rolling with lower pressure.

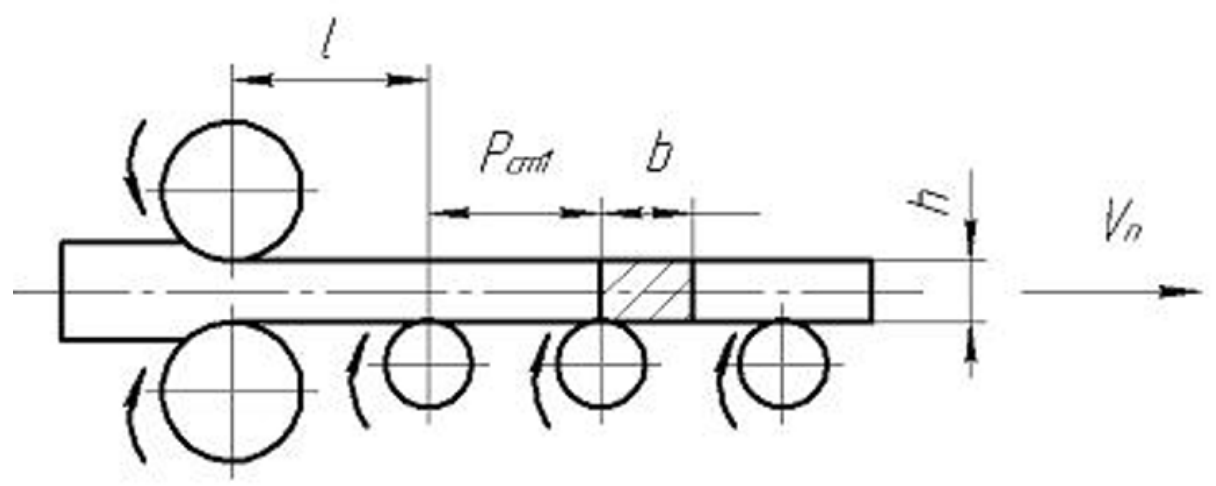

Fig. 6. Scheme of roller table loading when the billet is output from mill rolls.

The billet is fed onto the rollers from the above when the rolling is performed with the lower pressure. If the billet is bent at the stand output it rests against the roller and as the result the rollers can slip. 
The scheme of influence of the forces when the billet rests against the roller is shown in figure 7.

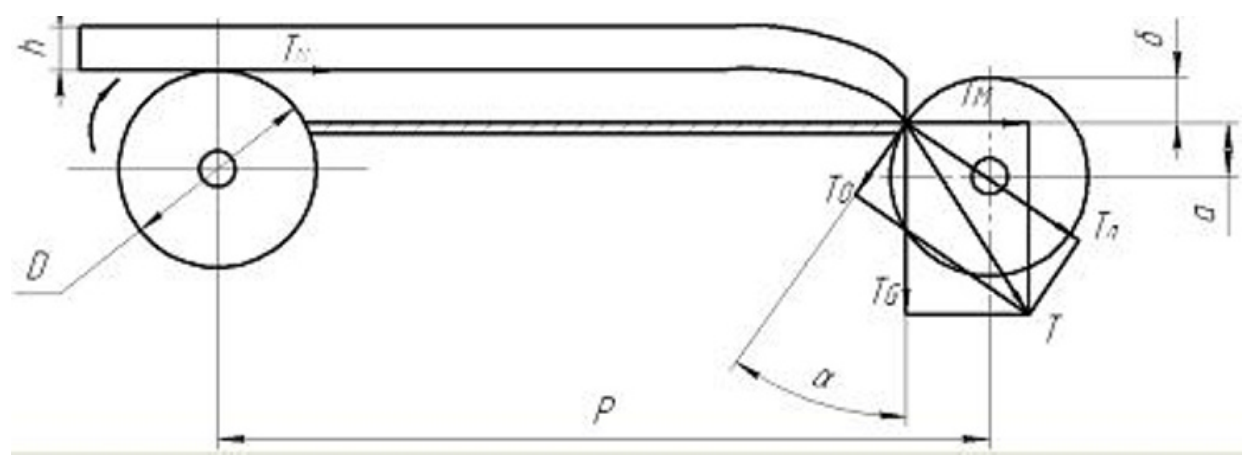

Fig. 7. The scheme of influence of the forces when the billet rests against the roller.

The electrical motors parameters of the roller table of wide-strip and plate mills are chosen in accordance with recommendations $[5,6]$. Specific attention is given to defining the metal weight per one roller. The particular feature of the calculation given in the above mentioned recommendations is that the calculation of the billet mass per conveyor roller is performed by dividing the entire mass of the billet by the number of the conveyor roller on which the billet rests.

In accordance with the source [7] the recommendations given in Table 1 [5] are usually taken into account to calculate the metal weight per one roller when designing electrical drives of the roller table.

Table 1. Calculated values of the proportion of metal weight per roller of the roller table, in accordance with the data

\begin{tabular}{|l|c|}
\hline \multicolumn{1}{|c|}{ Process workpiece characteristics } & $\begin{array}{c}\text { Weight portion } \\
\kappa=\mathrm{G}_{\mathrm{m}} / \mathrm{G}_{\mathrm{sl}}\end{array}$ \\
\hline 1. Billet with the section more than1000 $\mathrm{mm} 2$ and with the length less than 3 & 0.75 \\
\hline 2. Strips with the section more than $2000 \mathrm{~mm} 2$ and with the length more than & 0.5 \\
\hline 3. Strips with the section more than $2000 \mathrm{~mm} 2$ and with the length more than & 0.3 \\
\hline 4. Billets and thin strips with the length more than 9 roller spacings & $\begin{array}{c}\text { Weight per length } \\
\text { of 3 roller spacings }\end{array}$ \\
\hline
\end{tabular}

As there are a lot of methods to determine the weight of the metal per conveyor roller it is of interest to distribute its weight more accurately, it will allow to minimize the nominal characteristics of the selected electric motor - power, weight and cost and to meet the requirements for the reliability of the roller table.

To minimize characteristics while selecting an electric motor - power, weight and cost and at the same time to meet the requirements for the reliability of the roller table it is of interest to distribute weight of the workpiece onto the roller table rollers more accurately.

If the number of supports on which the workpiece rests is known, the average weight per support is determined by dividing the weight of the metal by the number of supports, reduced by one. The number of supports according to source [8] can be calculated on the basis of plastic deflection.

It is necessary to consider the scheme of location of the billet $[9,10]$ with the front end bent upwards and a support at point $O$, as shown in figure 8 . 


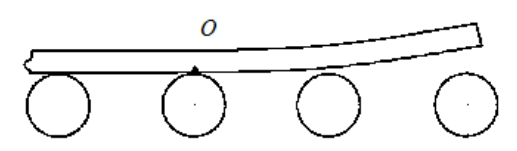

Fig. 8. The scheme of location of the billet during its conveying with the bent upward front end.

To calculate the length of the front end at which the plastic deformation will be caused by its own weight and the workpiece will get one more support we represent the front end of the billet in the form of a clamped beam, shown in Figure 9.

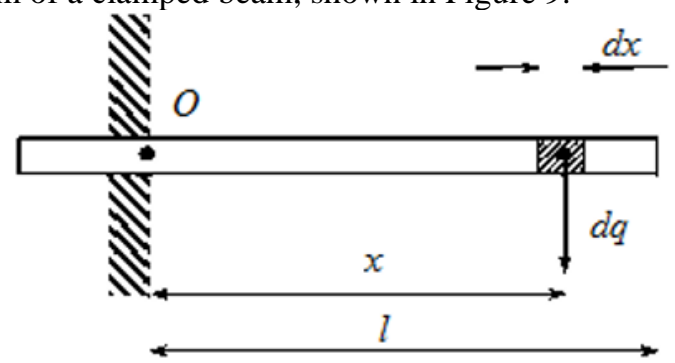

Fig. 9. Scheme of the billet in the form of a clamped beam.

Here the moment of deflection depending on the billet weight at point $\mathrm{O}$ equals:

$$
\mathrm{M}_{\mathrm{def}}=\mathrm{B} \cdot \mathrm{h} \cdot \gamma \cdot \mathrm{g} \cdot \mathrm{l}^{2} / 2
$$

where B is the billet width;

$h$ - billet thickness;

$\gamma$ - billet material density;

$\mathrm{g}=9,81 \mathrm{~m} / \mathrm{s} 2$;

1 - length of the clamped beam.

The deformation of the front end begins at the moment when the stresses on the surface reach the value of the yield point of $\delta \mathrm{S} 0$. The diagram of stresses in the cross-section of the billet is shown in Figure 10.

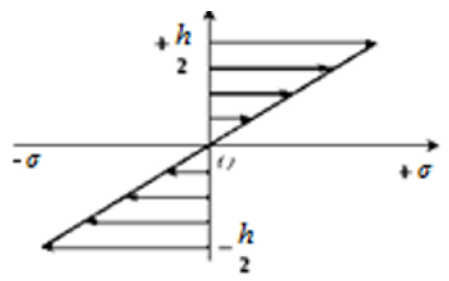

Fig. 10. The diagram of stresses in the cross-section of the billet.

The moment of plastic bending of the workpiece surface for a given stress diagram has the form:

$$
\mathrm{M}_{\text {pl.bend. }}=\delta_{s 0} \cdot \mathrm{B} \cdot\left(\mathrm{h}^{2}\right) / 6
$$

The maximum length of the front end of the workpiece, at which plastic bending occurs, is calculated by formulae (5) and (6), while the front end will acquire additional support:

$$
\mathrm{l}_{\max }=\sqrt{ } \delta_{S 0} \cdot \mathrm{h} / 3 \cdot \gamma \cdot \mathrm{g}
$$

Minimum number of supports, providing that $\mathrm{l}_{\max } \geq 1_{\mathrm{II}}$ and taking into account acquired support will be equal to: 


$$
\mathrm{n}_{1}=\left(\mathrm{Lr}-\mathrm{l}_{\max }\right) / \mathrm{l}_{\mathrm{m}}+2,
$$

where $\mathrm{l}_{\mathrm{w}}$ - value of conveyor rollers spacings;

$\mathrm{Lr}$ - roller table length.

Weight of the metal $G_{m}$ per roller when the slab weights $G_{s l}$ equals to:

$$
\mathrm{G}_{\mathrm{m}}=\mathrm{G}_{\mathrm{sl}} /\left(\mathrm{n}_{1}-1\right)=\mathrm{G}_{\mathrm{sl}} \cdot 1_{\mathrm{w}} /\left(\mathrm{L}_{\mathrm{r}}-\mathrm{l}_{\max }+\mathrm{l}_{\mathrm{w}}\right),
$$

If both ends of the billet are bent then the minimum number of supports with the acquired supports due to plastic bending of the front and rear ends of the billet will be equal to:

$$
\mathrm{n}_{2}=\left(\mathrm{L}_{\mathrm{r}}-2 \cdot 1_{\max }\right) / \mathrm{l}_{\mathrm{\omega}}+3,
$$

In this case the weight of metal per roller equals to:

$$
\mathrm{G}_{\mathrm{m}}=\mathrm{G}_{\mathrm{sl}} /\left(\mathrm{n}_{2}-1\right)=\mathrm{G}_{\mathrm{sl}} \cdot \mathrm{l}_{\mathrm{WI}} /\left(\mathrm{L}_{\mathrm{r}}-2 \cdot 1_{\max }+2 \cdot 1_{\mathrm{m}}\right)
$$

Equations (8) - (11) are applicable for the case when the billet rests on rollers and does not have bent sections.

Bent areas are possible for long billets in the middle.

The scheme of a billet with the bending in the middle and support at the points $O_{1}$ and $\mathrm{O}_{2}$ is shown in figure 11 .

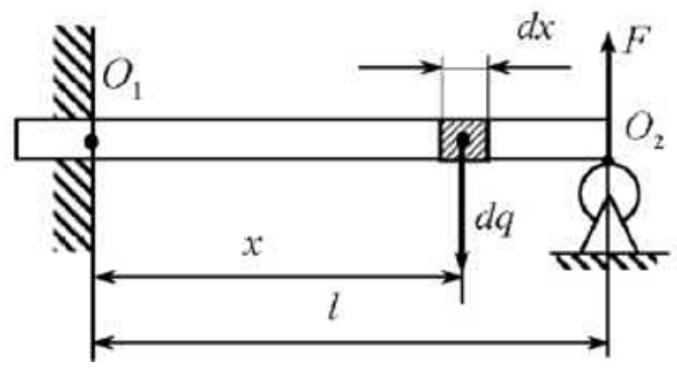

Fig. 11. Calculation of the metal weight per roller while conveying the billet with the bending in the middle.

Overriding the slipping torque occurred at roller necks of the roller tables without switching off the electrical motors is an essential condition for the reliable operation of the roller tables.

The slipping torque at a roller neck can be calculated as following:

$$
\mathrm{M}_{\sigma}=1.05 \cdot \mathrm{F}_{\sigma} \cdot \mathrm{D}_{\mathrm{p}} / 2=1.05 \cdot \mathrm{G}_{\mathrm{m}} \cdot \mu_{\sigma} \cdot \mathrm{D}_{\mathrm{p}} / 2,
$$

where $F_{\sigma}$ - slipping force at working surface of conveyor rollers;

$\mathrm{D}_{\mathrm{p}}$ - functional diameter of conveyor rollers;

1,05 - coefficient that takes into account the friction in the conveyor roller bearings;

$\mathrm{G}_{\mathrm{m}}$ - the weight of the workpiece per conveyor rollers;

$\mu_{\sigma}$ - friction coefficients when the conveyor rollers slips against the billet.

It can be seen from the equations that the slipping torque mainly depends on the accuracy of determining the weight of the metal $\mathrm{G}_{\mathrm{m}}$., per one conveyor roller.

$$
\mathrm{l}_{1 \max }=2 \sqrt{ } \delta s_{0} \cdot \mathrm{h} / 3 \cdot \gamma \cdot \mathrm{g}
$$

Maximum distance between the supports taking into account one formed support due to plastic bending between points $O_{1}$ and $\mathrm{O}_{2}$ will be equal to: $\mathrm{l}_{\max } / 2$. Based on comparison of two equations (8) and (13) it is seen that $l_{1 \max }=2 \cdot l_{\max }$. 
The minimum number of support for long bent billet can be calculated as following:

$$
\mathrm{n}_{3}=\left(2 \cdot \mathrm{L}_{\mathrm{r}} / 11_{\max }\right)+1=\mathrm{L}_{\mathrm{r}} / 1 \max +1
$$

Accordingly the weight of metal per roller equals to:

$$
\mathrm{G}_{\mathrm{m}}=\mathrm{G}_{\mathrm{sl}} \cdot \mathrm{l}_{\text {max }} / \mathrm{L}_{\mathrm{r}}
$$

Equations (14) and (15) allow to calculate the minimum number of supports and metal weight per a roller if the billet is bent in the middle and at the both ends[11].

To calculate the weight of the metal per roller it is convenient to use the relative value $G_{m}{ }^{\prime}$, that is, the relation of the weight of the metal per one roller $G_{m}$ to the minimum metal weight $G_{m} \cdot \min$, corresponding to the weight of the metal between two adjacent rollers of the roller table.

Minimum weight of the metal equals:

$$
\mathrm{G}_{\mathrm{m} \cdot \min }=\mathrm{G}_{\mathrm{sl}} \cdot \mathrm{l}_{\mathrm{wl}} / \mathrm{L}_{\mathrm{r}} \text {. }
$$

If the equations (10), (12) and (15) are divided by equation (16) after conversion we will get equations to calculate relative weight of the metal per one roller table roller:

if $\mathrm{L}_{\mathrm{r}}=(2 \div 3) \cdot 1_{\max }$, the billet has one bent end:

$$
\mathrm{G}_{\mathrm{m}}{ }^{\prime}=1 /\left[1-\left(\mathrm{l}_{\max }-\mathrm{l}_{\mathrm{w}}\right) / \mathrm{L}_{\mathrm{r}}\right]
$$

if $\mathrm{L}_{\mathrm{r}}=(2 \div 3) \cdot 1_{\max }$, the billet has two bent ends:

$$
\mathrm{G}_{\mathrm{m}}{ }^{\prime}=1 /\left[1-\left(\mathrm{l}_{\max }-\mathrm{l}_{\mathrm{w}}\right) / \mathrm{L}_{\mathrm{r}}\right] \text {; }
$$

if $L_{r}>3 \cdot 1$ max, the billet is bent along its length and it has bent ends as well:

$$
\mathrm{G}_{\mathrm{m}}{ }^{\prime}=\mathrm{l}_{\max } / \mathrm{l}_{\mathrm{m}}
$$

\section{Summary}

The paper shows information on how to calculate the loads on conveyor roller at different billet positions. It allows to calculate slipping torque arising during conveying of the billet more precisely and to minimize the parameters of electrical motors drives for conveyor rollers.

\section{References}

1. V. D. Zadorozhny, Standardized carry-over table with increased maintainability and individual drive: Abstract from thesis research of Candidate of Science EngineeringMagnitogorsk,2006.

2. V. B. Chuprov, Z. P, Karetny, N. Z. Tretyakov, refurbishment of metallurgical production. Modern equipment of rolling plants wide-strip hot rolling mill. Study guide - Lipezk, 2007.

3. V.S. Glazov, Mechanisms for continuous conveying for rolling process.M.:"Metallurgy", 1979.

4. F. K.Ivanchenko, V. M.Grebenik, B.I.Shiryaev, role of machines and mechanisms in rolling shops -K.:Vysshaya shk, 1995.

5. A. I. Zelikov, P. I. Polukhin, V. M. Grebenik , Machines and units of metallurgical plants: Study guide for universities. In 3 volumes, Vol. 3.Machines and units for production and finishing of the rolled products [and others].- M.:Metallurgy,1988. 
6. A. A. Korolev, Design and engineering of the mechanisms and machines of rolling mills / - M.: Metallurgy.- 1985.

7. N. N. Druzhinin Electrical equipment of rolling plants - M.: Metallurgizdat, 1956.

8. M. A. Sonkin, Research of individual electric drive of roller table rollers. Vol. 80 Rolling mills -M.: Mashgiz, 1956.

9. M. V. Androsenko E. V. Kulikova, Calculation of the load on the rollers of the rolling mill roll during workpiece conveying, Mechanical Equipment of Metallurgical Plants: International collection of scientific papers / edited by A. G. Korchunov №1. Magnitogorsk: publishing office of Magnitogorsk State Technical University named after G. I. Nosov (2020) 39-46.

10. Tyuteryakov Nail Sh., Savinov Alexander S., Androsenko Maria V., Rud Ksenia I., Zalilov Rustem V., Calculation of forces on the twist rollers of RTC guide fittings of PAO "MMK" section rolling mills in the process of strip coiling, Theory and technology of metallurgical production: Nosov Magnitogorsk State Technical University, Magnitogorsk, Russia (2020) 47-49.

11. Androsenko, M., Kulikova, E., Tyuteryakov, N., Pashenko, K., Yaroslavtsev, Determining the quality of continuous casting from billet caster A. E3S Web of Conferences, 110 (2019) 01034 